\title{
Noncontingent exposure to the unconditioned stimulus attenuates state-dependent memory loss
}

\author{
SUSANNE M. MEEHAN, TIMOTHY L. GORDON, and DAVID C. RICCIO \\ Kent State University, Kent, Ohio
}

\begin{abstract}
Animals trained on an aversively motivated one-trial passive avoidance task were given pretraining administration of either hypothermia or a novel drug state $(15.0 \mathrm{mg} / \mathrm{kg}$ pentobarbital). Both of these exposures produced marked deficits for training memory, relative to controls, at a 24-h test. These memory deficits were alleviated by pretest noncontingent exposure to the training footshock. However, in the case of the state-dependent retention produced by pentobarbital, successful alleviation of the amnestic effects required an increase in the intensity and number of reminder presentations and/or compounding noncontingent exposure to the unconditioned stimulus with an additional exposure to the training apparatus. These results further support the notion that the memory impairments produced by pharmacological state-dependent retention may be characteristically similar to those produced by anterograde hypothermia. The results are discussed in terms of traditional notions of pharmacological state dependency, which contend that memory deficits can be reduced only by reintroduction of the drug state that is present at training.
\end{abstract}

A number of studies have shown that the amnestic effects of manipulations such as electroconvulsive shock (ECS) or thermoregulatory disruption can be attenuated by a second administration of the same treatment prior to testing (Ahlers \& Riccio, 1987; Hinderliter, Webster, \& Riccio, 1975; Mactutus, McCutcheon, \& Riccio, 1980; Mactutus \& Riccio, 1978; Richardson, Guanowsky, Ahlers, \& Riccio, 1984; Thompson \& Neely, 1970). This reversal or attenuation of amnesia has been obtained whether the memory loss was induced by a posttraining (retrograde amnesia) or pretraining (anterograde amnesia) treatment. These findings have fostered the notion that amnestic agents might provide a specific internal context, or state, that is incorporated with the target memory at the time of training (Hinderliter et al., 1975). Thus, the reinstatement of this endogenous cue at the time of testing should facilitate retrieval of the target memory (Spear, 1978, 1981). This "context bound" or "state-dependent" interpretation of amnestic action was first proposed over 20 years ago (DeVietti \& Larson, 1971; Mayes \& DeVietti, 1971; Nielson, 1968). It is similar to the notion of pharmacological state-dependent retention (SDR) that was proposed by Overton (1968, 1984) to account for variations in retrieval of a target memory as a function of the presence of specific druginduced states at training and testing. Although the parallelism between anterograde amnesia (AA) and SDR is apparent--both involve exposure to a treatment (e.g., ECS, drug) prior to acquisition-similar processes may be involved, even in posttraining manipulations. For ex-

The research reported in this paper was supported in part by NIMH Grant 37535 to D.C.R. Address correspondence to S. M. Meehan, Department of Pharmacology, Northeastern Ohio Universities, College of Medicine, 4209 State Rt. 44, P.O. Box 95, Rootstown, OH 44272. ample, under certain conditions, administrations of a state-dependent agent following training can produce memory deficits that are similar to those seen in retrograde amnesia (RA; Chute \& Wright, 1973; Richardson, Riccio, \& Steele 1986; Wright \& Chute, 1973).

Additionally, amnestic treatments and state-dependent drugs often have been found to produce asymmetrical results at testing. That is, animals that are trained in the presence of an amnestic agent or drug and tested in its absence show poor memory for the target episode. However, subjects that are trained under normal conditions and tested under the influence of the agent or drug typically exhibit good retention of the target memory (Berger \& Stein, 1969; Hinderliter et al., 1975; Overton, 1968; Santucci \& Riccio, 1987).

These commonalities between the two phenomena strengthen the proposition that traditional amnestic agents as well as state-dependent drugs may exert their memorial effects through a common mechanism of action - that is, by providing at the time of training a distinctive internal cue that must be matched at testing in order to promote retrieval of the target memory (Nielson, 1968; Spear, 1981).

At the same time, however, research in the RA paradigm has made it clear that other stimulus attributes related to the training episode can serve as effective retrieval cues. Thus, the attenuation of RA has been demonstrated with pretest exposure to either the training conditioned stimulus (CS; DeVietti \& Hopfer, 1974; W. C. Gordon \& Mowrer, 1980) or the unconditioned stimulus (US; Miller \& Springer, 1972). Reversal of RA by noncontingent reexposure to the training reinforcer or US has become a particularly potent and widely used manipulation, and results from a number of studies have shown that noncontingent footshock (NCFS) will alle- 
viate RA (e.g., Mactutus, Ferek, \& Riccio, 1980; Miller \& Springer, 1972; Quartermain, McEwen, \& Azmitia, 1970).

Interestingly, relatively little attention has been given to the question of whether treatments such as NCFS will also serve to alleviate the memory loss that is associated with AA and SDR. Richardson, Riccio, and Morilak (1983) found that NCFS did produce increments in retention scores, but failed to significantly reverse the AA induced by hypothermia. However, as the investigators noted, this "negative result" is difficult to interpret because only a single set of parametric values was employed. Thus, further examination of this issue is clearly warranted.

Therefore, the present study had two closely related aims: (1) to attempt to attenuate hypothermically induced AA by pretest exposure to NCFS (i.e., attributes of the US), and (2) to determine whether such a reminder effect could be extended to a pharmacological SDR paradigm.

\section{EXPERIMENT 1}

In Experiment 1, we examined attenuation of hypothermically induced anterograde amnesia by pretest administration of NCFS. Procedurally, the experiment closely resembled that of Richardson et al. (1983), but we modified the way the hypothermic temperature was achieved, as well as the footshock characteristics used during training and reactivation.

\section{Method}

Subjects. Sixty adult male Sprague-Dawley rats, purchased from Holtzman Co., served as subjects. The animals were 70-90 days of age at the time of training. They were housed in hanging wiremesh cages, with food and water available ad lib.

Apparatus. Training and testing were conducted in a Plexiglas box divided into two equal compartments $(47.5 \times 19.0 \times$ $22.0 \mathrm{~cm}$ ). One compartment, including the lid, was painted black, and the other compartment was white with a clear lid. The compartments were separated by a guillotine door. The floor of the apparatus consisted of stainless steel rods that were $2.0 \mathrm{~mm}$ in diameter and spaced $1.0 \mathrm{~cm}$ apart. The rods on the black side were wired to a constant-current shock source (Lafayette Instrument Co., Model 58006) equipped with neon scramblers. The training room was dimly illuminated by a $15-\mathrm{W}$ light bulb that was suspended $30.0 \mathrm{~cm}$ above the white side of the apparatus. A whitenoise generator set at $15.0 \mathrm{~dB}$ was employed during training and testing to mask extraneous auditory cues.

The noncontingent footshock apparatus consisted of a clear Plexiglas box $(18.0 \times 16.5 \times 16.5 \mathrm{~cm})$ equipped with a plywood insert of approximately the same dimensions. The floor of the apparatus consisted of $2.0-\mathrm{mm}$ stainless steel rods positioned $1.0 \mathrm{~cm}$ apart. The rods were wired to a shock source that was identical to that used in training and testing. The apparatus was located in a room that was separate from the one with the training apparatus. NCFS was administered in the absence of white noise and under full room illumination.

Procedure. The animals were handled 3-5 min per day on the 2 days preceding training. On Day 3 , the animals were divided into six groups. The first group, a retention control group (PA-ONLY), received one trial of passive avoidance training. This training consisted of placing the animal in the white side of the black/white shuttle apparatus for $15 \mathrm{sec}$. After this time, the door between the compartments was raised and the animal was allowed to freely locomote into the black side, where it received a $0.8-\mathrm{mA}, 3-\mathrm{sec}$ inescapable footshock. The animal was then removed from the black side and returned to the home cage. The second group, the amnesia group (HYPO-PA), received anterograde hypothermia and passive avoidance training. Hypothermia was induced by confining the animal in a clear Plexiglas cylinder and immersing it, up to its neck, in a $3^{\circ}-4^{\circ} \mathrm{C}$ water bath until colonic temperature, measured by a Fischer Scientific Digital Thermometer, dropped to $29^{\circ} \mathrm{C}$. Upon removal from a bath, body temperature continues to decline several degrees; therefore, the animals were allowed to rewarm to $29^{\circ} \mathrm{C}$ and were then given one passive avoidance training trial.

The third group, the reactivation group (HYPO-PA-NCFS), received anterograde hypothermia, passive avoidance training, and a noncontingent footshock reminder treatment that was administered $30 \mathrm{~min}$ prior to test. This reminder treatment consisted of confining the animal in the NCFS apparatus for $1 \mathrm{~min}$. During this time, the animal received three $0.8-\mathrm{mA}, 3-\mathrm{sec}$ footshocks, delivered at 20,30 , and $40 \mathrm{sec}$. The animal was then removed from the apparatus and returned to the home cage until testing.

The remaining three groups served as control groups to assess the potential activational and nonassociative effects of the NCFS reminder. The first group, $\mathrm{PA}-\mathrm{NCFS}$, received passive avoidance training and an NCFS reminder 30 min prior to testing. The second group, NCFS-ONLY, received the NCFS before testing, but was not given any passive avoidance training. The final group, HYPONCFS-NCFS, received all of the treatments that the experimental group had received, except the "training" shock was not paired with black cues. Thus, following hypothermia treatment, the rats in this condition received a backward pairing of a single, 3-sec, $0.8-\mathrm{mA}$ noncontingent footshock that was followed immediately by exposure to the black/white apparatus. This exposure was identical to that employed in the training groups, with one exceptiononce the animal moved into the black side, it was confined there for $30 \mathrm{sec}$ in the absence of footshock. The subjects in this group also received NCFS reactivation 30 min before testing.

All of the animals were tested $24 \mathrm{~h}$ after training with NCFS (in the designated groups) occurring $30 \mathrm{~min}$ before testing. Testing consisted of a 10 -min passive avoidance task in the black/white apparatus. The animal was placed in the white compartment for $15 \mathrm{sec}$, after which time the door between the compartments was raised, allowing the animal access to both compartments. The total time spent on the white side (TTW) during the 10 -min period served as the dependent measure.

\section{Results and Discussion}

Due to the large number of ceiling scores obtained, the data were analyzed with nonparametric tests. A KruskalWallis analysis of variance (ANOVA) indicated no differences between the groups in their latency to enter the black side during training $(H=3.13, p>.05)$. A Kruskal-Wallis ANOVA performed on the test scores indicated a significant treatment effect $(H=25.0, p<.01)$. Further analysis, employing Mann Whitney $U$ tests corrected for ties, revealed that the NCFS reminder attenuated the amnesia produced by anterograde hypothermia. As can be seen in Figure 1, the animals in the HYPO-PA group exhibited anterograde amnesia with shorter TTW scores-that is, poorer retention than the animals in the $\mathrm{PA}$ and PA-NCFS groups $(z=2.79, p<.01 ; z=2.66, p<$ .01 ). This amnesia was alleviated by NCFS treatment, as can be seen by the TTW scores in the HYPO-PA-NCFS group, which were longer than those in the HYPO-PA group $(z=2.57, p<.01)$. The magnitude of the recov- 


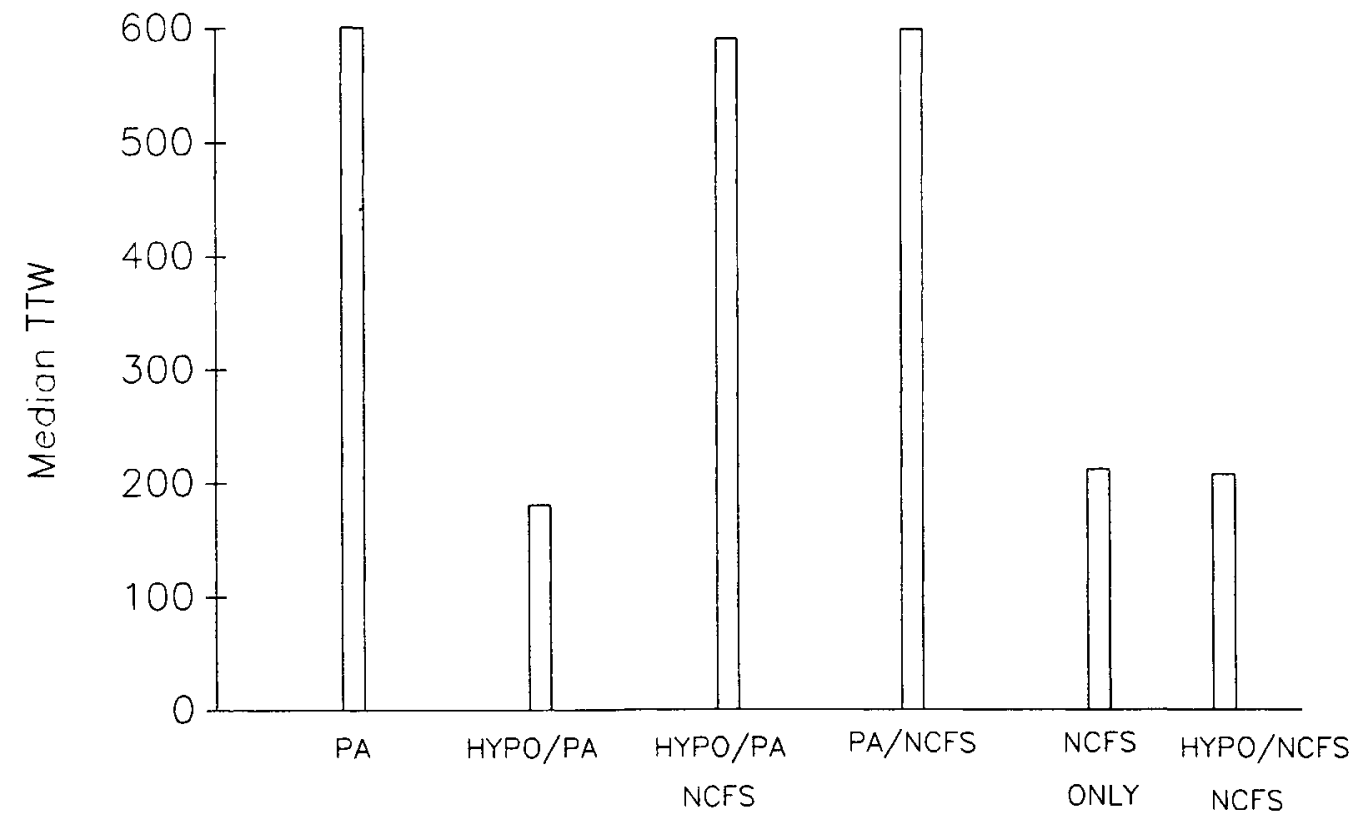

Figure 1. Retention scores (median total time on the white side; TTW) for animals given passive avoidance (PA) training, anterograde hypothermia (HYPO/PA), anterograde hypothermia with 0.8 -mA noncontingent footshock reactivation (HYPO/PA/NCFS), training and reactivation (PA/NCFS), reactivation alone (NCFS ONLY), and anterograde hypothermia followed by pseudotraining and pretest reactivation (HYPO/NCFS/NCrs).

ery is reflected in the finding that the HYPO-PA-NCFS group performed as well as the groups that were trained in the absence of the amnestic treatment, specifically PAONLY and PA-NCFS $(z=1.38, p>.05 ; z=.802, p>.05)$.

Furthermore, the recovery observed in the HYPO-PANCFS group was not a function of activational or nonassociative effects of the NCFS, since the animals in the NCFS-ONLY and HYPO-NCFS-NCFS groups exhibited retention scores that were much lower than those observed in the HYPO-PA-NCFS group $(z=2.99, p<.01 ; z=2.80, p<$ .01 , respectively).

These results indicate that memory deficits produced by anterograde amnesia can be attenuated by noncontingent presentations of the footshock US prior to testing. It should be noted, however, that successful reactivation of the amnestic memory was obtained after three noncontingent presentations of the footshock. The failure to obtain reactivation reported by Richardson et al. (1983) was based on a single noncontingent presentation of the training footshock during the reactivation treatment. This single presentation is typically sufficient to produce recovery from amnesia induced by the retrograde administration of the agent (Hinderliter et al., 1975; Mactutus, Ferek, \& Riccio, 1980). Although paradigmatic differences prevent precise comparisons, in the case of hypothermically induced amnesias, the anterograde preparation may be quantitatively different from the retrograde situation. Thus, it is possible that the anterograde condition produces a greater stimulus control, which, in turn, requires a more "potent" reminder to attenuate the memory deficit. But more importantly, the finding that noncontingent exposure to the US attenuates AA provides another point of similarity with the RA phenomenon.

\section{EXPERIMENT 2}

The hallmark characteristic of SDR is the reversal of a memory deficit by reinstatement of the pharmacological state that is present at original training. Thus, when subjects are trained after the administration of a drug and tested without the drug, retention is impaired; readministration of the drug prior to testing produces recovery of the response. Accordingly, a number of researchers have examined the functional similarity of related drugs by determining the extent to which a new agent can substitute for the original drug at testing (e.g., Overton, 1964, 1968). Perhaps because of this focus, little attention has been given to the possibility that nonpharmacological treatments might also produce memory recovery. Indeed, much of the research literature seems to assume that SDR is based entirely on altered pharmacological stimuli. But the finding that noncontingent US exposure can alleviate amnesia, as seen in Experiment 1 and elsewhere (DeVietti \& Bucy, 1975; Hinderliter et al., 1975; Mactutus, Ferek, \& Riccio, 1980; Miller \& Springer, 1973, 1974), encourages the view that a similar outcome might be obtained in SDR. The aim of Experiments 2 and 3 was to determine whether noncontingent US exposure prior to testing would alleviate the deficit produced by a shift in pharmacological state-that is, drug to nondrug. 


\section{Method}

Subjects. Fifty adult male Sprague-Dawley rats, purchased from Holtzman Co., served as subjects. The animals were 70-90 days old at the time of training, and housing and maintenance were identical to that in Experiment 1.

Apparatus. The training and ncfs apparatus employed in this experiment were identical to those used in Experiment 1 .

Procedure. All the animals were handled for 3-5 min per day for 2 days prior to the start of the experiment. On Day 3, the animals were divided into five groups. All the animals received a 15.0$\mathrm{mg} / \mathrm{kg}$ intraperitoneal (i.p.) injection of pentobarbital $30 \mathrm{~min}$ prior to training. Training and testing was identical to that in Experiment 1.

The groups differed on the basis of the treatment that they received $30 \mathrm{~min}$ prior to testing. The animals in the first group, PENTO-PENTO, were given a second $15.0-\mathrm{mg} / \mathrm{kg}$ i.p. injection of pentobarbital prior to testing. Thus, these animals, which received pentobarbital before both training and testing, served as the drug-drug group that is typically employed in the SDR paradigm. The second group, PENTO-SAL, was given i.p. injections of saline before testing and represented the drug-no-drug "amnesia" condition. The animals in the third group, the reactivation group (PENTONCFS), were given three 3-sec noncontingent footshocks of $0.8 \mathrm{~mA}$ intensity. The subjects in the fourth group, another reactivation group (PENTO-NCFS+B) received noncontingent footshocks that were identical to those given to the PENTO-NCFS group; however, footshock was followed by a 30 -sec exposure to the black side of the training apparatus in contextual conditions that were identical to those present at training. Thus, the reactivation treatment consisted of US, apparatus, and room cues, but in a Pavlovian "backward" order. The final group, PENTO-HYPO, was given hypothermia to a colonic temperature of $29^{\circ} \mathrm{C}$ and allowed to rewarm to $29^{\circ} \mathrm{C}$ prior to testing. This group was included to control for the effects of systemic stress on recovery from SDR.

\section{Results and Discussion}

A Kruskal-Wallis ANOVA revealed no differences in the training latencies between the groups $(H=2.27, p>$
.05). A second Kruskal-Wallis ANOVA conducted on the TTW scores obtained in Experiment 2 yielded a significant treatment effect $(H=14.94, p<.01)$. MannWhitney $U$ comparisons isolated this effect as better performance in the PENTO-PENTO group relative to all other groups. As can be seen in Figure 2, the animals in the PENTO-PENTO group exhibited longer TTW scores (i.e., better retention) than the subjects in the PENTO-SAL condition $(z=2.8, p<.01)$, indicating no observable deficit in learning and establishing attenuation of the SDR deficit by a second, pretest administration of the drug. However, the animals in the PENTO-PENTO group also performed significantly better than those in either of the reactivation groups, PENTO-NCFS and PENTO-NCFS+B $(z=$ $2.56, p<.01 ; z=1.6, p<.05)$. This finding, coupled with the fact that the PENTO-NCFS and PENTO-NCFS+B groups did not differ from PENTO-SAL $(z=.89$ and $z=$ .82 , respectively), suggests that both of the reactivation treatments failed to attenuate the memory deficits produced by pentobarbital-induced SDR. Additionally, there was no effect of systemic stress on memory retrieval. The animals in the PENTO-HYPO group exhibited poorer performance than that of the animals in the PENTOPENTO group.

These data indicate that the reactivation procedures that were employed failed to facilitate retrieval of a memory that had been encoded under the influence of pentobarbital. However, it is possible that the failure reflects insufficient reactivation conditions rather than irreversibility of memory loss. For example, the internal context produced by a pharmacological agent might be particularly salient, and thus exert greater stimulus control, resulting in a very strong amnestic effect. In this

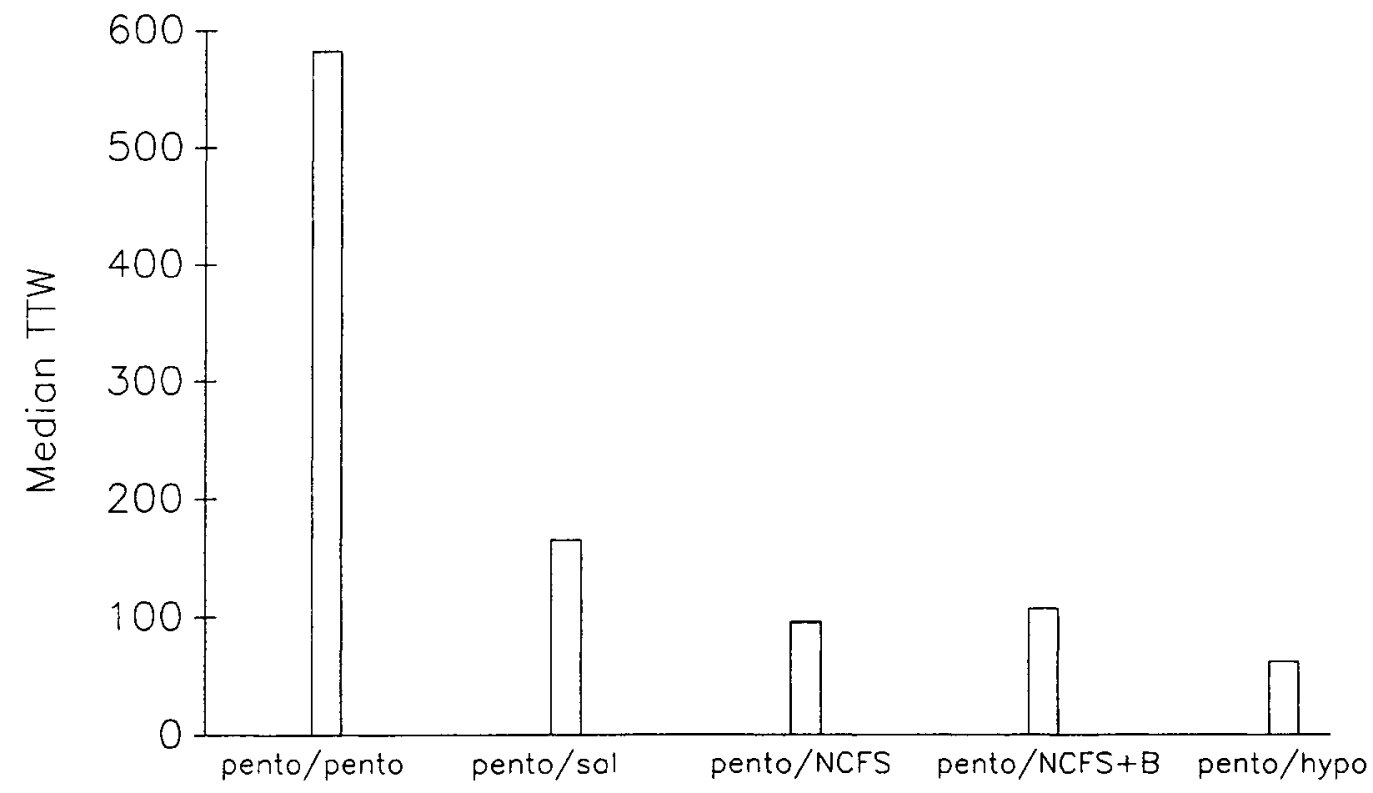

Figure 2. Retention scores (median total time on the white side; TTW) for animals trained under the influence of $15.0 \mathrm{mg} / \mathrm{kg}$ pentobarbital and given pentobarbital (pento/pento), saline (pento/sal), 0.8-mA noncontingent footshock (pento/NCFS), noncontingent footshock followed by exposure to the black side of the training apparatus (pento/NCFS $+\mathrm{B}$ ), or hypothermia (pento/hypo) prior to testing. 
case, a highly salient retrieval cue might be required to reactivate the target memory. Therefore, in Experiment 3, the effects of NCFS reactivation of memory in the SDR paradigm were examined by using a more intense reactivating stimulus.

\section{EXPERIMENT 3}

\section{Method}

Subjects. The subjects were 64 adult male Sprague-Dawley rats, $70-90$ days of age at the time of training. Housing and maintenance were identical to that in the previous experiments.

Apparatus. The apparatus was identical to that used in the previous experiments.

Procedure. All of the animals were handled for 3-5 min per day for 2 days prior to training. On Day 3, the animals were divided into eight groups. Five of the groups were experimental groups, and three of the groups served as controls. The animals in all eight groups were given i.p. injections of $15.0 \mathrm{mg} / \mathrm{kg}$ pentobarbital $30 \mathrm{~min}$ before training. Training for the animals in the experimental groups was identical to that in the previous experiments. The animals in the control groups received pseudotraining, which consisted of a backward pairing of a single, 3-sec, 0.8-mA footshock followed by an exposure to the black/white training apparatus. This exposure was identical to the training exposure, with one exception. Following locomotion into the black side, the animal was confined there for $30 \mathrm{sec}$. No footshock was delivered. After pseudotraining, the animals were returned to their home cage.

All the animals were tested $24 \mathrm{~h}$ after training or pseudotraining. Thirty minutes before testing, each group received a specific manipulation. One experimental group (PENTO-PENTO) was administered a second $15.0-\mathrm{mg} / \mathrm{kg}$ i.p. injection of pentobarbital. Another group (PENTO-SAL) was given an i.p. injection of saline. The PENTO-3-NCFS experimental and control groups received a reactivation treatment, which consisted of a 1-min confinement in the NCFS apparatus. During this time they were given three, 3-sec,
1.0-mA footshocks at 20,30 , and 40 sec. Following this, the animals were returned to the home cage. Experimental and control animals in the PENTO-3-NCFS+B reactivation condition were given noncontingent footshocks that were identical to those given to the animals in the PENTO-3-NCFS groups. However, following NCFS, the animals were placed into the black side of the training apparatus (with visual and auditory room context identical to that present at training) for $30 \mathrm{sec}$ before being returned to the home cage. Thus, the reactivation treatment for the animals in the PENTO-3NCFS+B conditions consisted of US, apparatus, and room cues. Finally, experimental and control animals in the PENTO-5-NCFS condition were confined to the NCFS apparatus for $1 \mathrm{~min}$, where they received five, 3-sec, 1.0-mA footshocks delivered at 10, 20,30, 40 , and $50 \mathrm{sec}$. The animals were then returned to the home cage. Testing for all the animals was identical to that in the previous experiments.

\section{Results and Discussion}

Kruskal-Wallis ANOVAs indicated no effect of treatment on training latency $(H=2.02, p>.05)$. However, a significant treatment effect was observed $(H=43.59$, $p<.01$ ). As can be observed in Figure 3, Mann-Whitney $U$ comparisons indicated that the animals in the PENTOPENTO group performed significantly better than the animals given saline prior to test (PENTO-SAL; $z=3.37, p<$ .01 ). The scores of the experimental animals in all three of the reactivation conditions (PENTO-3-NCFS, PENTO-3NCFS $+\mathrm{B}$, and PENTO-5-NCFS) were higher than the scores of their respective controls $(z=2.21, p<.05 ; z=3.39$, $p<.01$; and $z=3.36, p<.01)$. Additionally, the PENTO3-NCFS+B and PENTO-5-NCFS animals attained a level of performance that was equivalent to that of the animals in the PENTO-PENTO group ( $z=.105, \mathrm{n} . \mathrm{s}$. and $z=.747$, n.s.). These animals also exhibited test scores that were

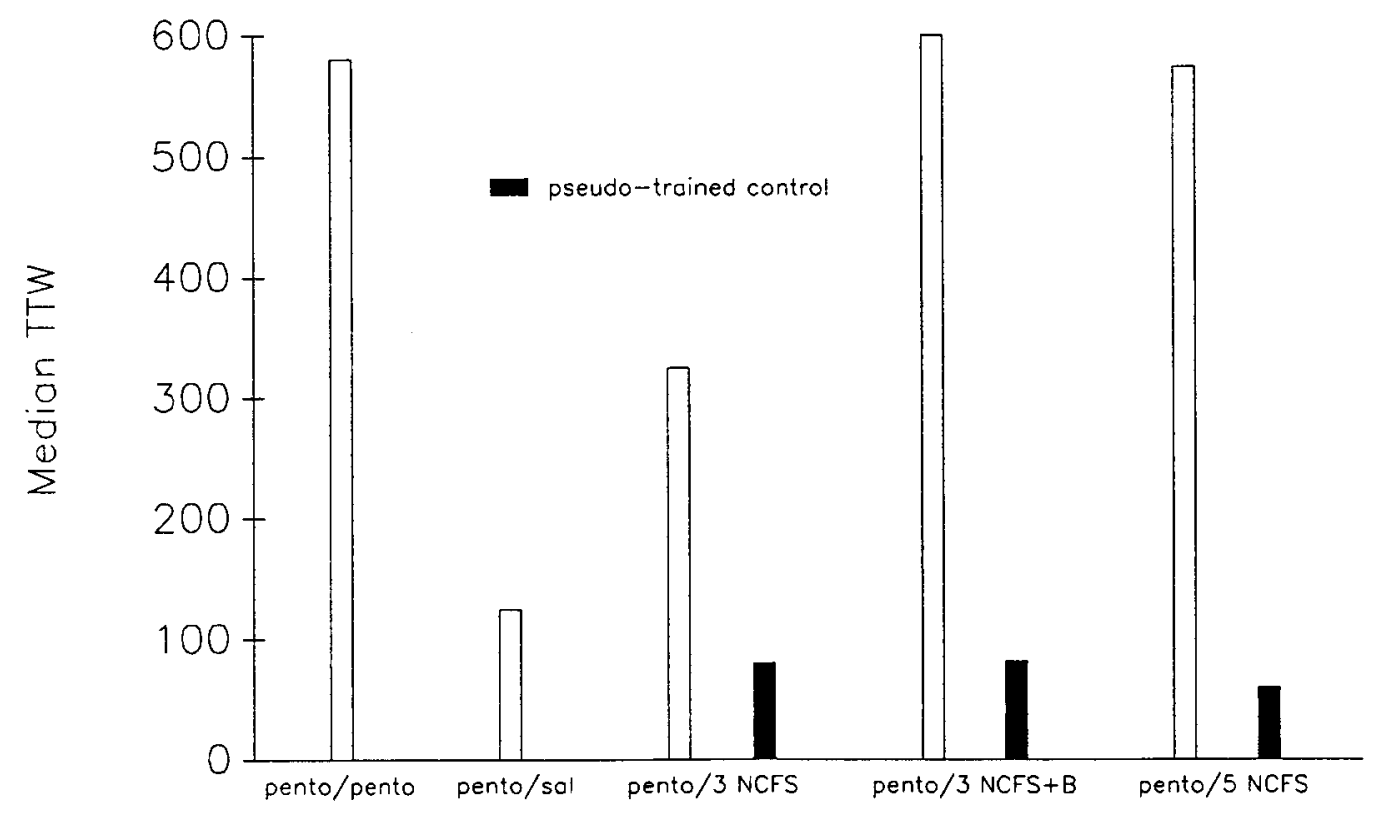

Figure 3. Retention scores (median total time on the white side; TTW) for animals trained under the influence of $15.0 \mathrm{mg} / \mathrm{kg}$ pentobarbital and given pentobarbital (pento/pento), saline (pento/sal), 1.0-mA noncontingent footshock (pento/3 NCFS and pento/5 NCFS), or noncontingent footshock followed by exposure to the black side of the apparatus (pento/3 NCFS+B) prior to testing. 
significantly higher than those of the animals in the PENTO-SAL condition $(z=3.36$, and $z=3.27, p<.01$, respectively), suggesting that these reactivation treatments successfully alleviated the memorial deficits in animals trained under the influence of pentobarbital.

These findings clearly indicate that memory disruptions produced by pharmacological shifts in internal context (i.e., drug to no drug) can be alleviated by the noncontingent presentation of the US prior to testing. Furthermore, in light of the findings obtained in Experiment 2, it appears that the reminder treatment may need to be particularly salient (i.e., increased intensity or frequency of the US attribute, or a more intense US reminder presented in conjunction with apparatus cues) to promote retrieval of a memory encoded under the influence of pentobarbital. However, it is equally plausible that a less potent dose of pentobarbital may have produced a degree of SDR commensurate with that observed with hypothermia and thus may have required a less salient reminder to produce reversal of SDR.

\section{GENERAL DISCUSSION}

As indicated in the introduction, one possible difference between AA and RA was the effectiveness of exposure to the US as a reminder treatment. The present study indicates that anterograde memory loss based on hypothermia can be alleviated by presentation of the US prior to testing. The finding that anterograde amnestic effects can be reversed by a pretest reminder treatment consisting of a US attribute provides an addition to the growing body of convergent evidence suggesting that anterograde and retrograde amnestic preparations may be functionally similar in their effects on memory processing.

A second, perhaps more provocative implication is posed by the finding that the retention deficits produced in the SDR paradigm can be alleviated by a nonpharmacological reactivation treatment. These data expand the traditional view of SDR effects, namely, that reversal of the memory deficit can be obtained only through pretest reinstatement of the original (or closely related) drug state (but see Connelly, Connelly, \& Phifer, 1975). Apparently, memory can be accessed after exposure to the attributes of the training reinforcer, as is also the case with other sources of forgetting (Haroutunian \& Riccio, 1977; Lashley, Richardson, \& Riccio, 1987; RoveeCollier \& Sullivan, 1980; Schachtman, Brown, \& Miller, 1985). Thus, this finding serves to strengthen the interpretation of commonalities between the actions of traditional amnestic agents and pharmacological agents in producing memory loss (e.g., Hinderliter et al., 1975; Mayes \& DeVietti, 1971; Nielson, 1968).

Finally, noncontingent footshock reactivation of statedependent memory provides a potentially useful methodological tool, permitting assessment of memory acquired under the influence of state-dependent agents without the "contamination" of drug effects presented at testing. For example, T. L. Gordon, Meehan, and Riccio (1989) employed NCFS reactivation of pentobarbital SDR to examine expression of memory for external contextual attributes encoded under training in the pentobarbital state. This procedure revealed that external contextual information had been encoded, since a shift in environmental context disrupted the reactivated performances. Because the effect of the drug at testing apparently masked the effects of a context shift, the reactivation with NCFS provided a more sensitive method for assessing this question.

\section{REFERENCES}

AHLERS, S. T., \& RICCIO, D. C. (1987). Anterograde amnesia induced by hyperthermia in rats. Behavioral Neuroscience, 101, 333-340.

BERGER, B., \& SteIN, L. (1969). Asymmetrical dissociation of learning between scopolamine and $\mathrm{Wy}_{\mathrm{y}} 4036$, a new benzodiazepine tranquilizer. Psychopharmacologia, 14, 351-358.

ChUte, D. L., \& WRIGHT, D. C. (1973). Retrograde state dependent learning. Science, 180, 878-880.

Connelly, J: F., Connelly, J. M., \& Phifer, R. (1975). Disruption of state-dependent learning (memory retrieval) by emotionally important stimuli. Psychopharmacologia, 41, 139-143.

DEVIETTI, T. L., \& BUCY, C. E. (1975). Recovery of memory after reminder: Evidence for two forms of retrieval deficit induced by ECS. Physiological Psychology, 3, 19-25.

DEVIETTI, T. L., \& HopFER, T. M. (1974). Reinstatement of memory in rats: Dependence upon two forms of retrieval deficit following electroconvulsive shock. Journal of Comparative \& Physiological Psychology, 86, 1090-1099.

DeVIETTI, T. L., \& LARSon, R. C. (1971). ECS effects: Evidence supporting state dependent learning in rats. Journal of Comparative \& Physiological Psychology, 74, 407-415.

Gordon, T. L., Meehan, S. M., \& Riccio, D. C. (1989, May). The effects of pentobarbital on responding to contextual shifts at testing. Paper presented at the meeting of the Midwestern Psychological Association, Chicago.

Gordon, W. C., \& Mowrer, R. R. (1980). An extinction trial as a reminder treatment following electroconvulsive shock. Animal Learning \& Behavior, 8, 363-367.

Haroutunian, V., \& Riccio, D. C. (1977). Effect of arousal conditions during reinstatement treatment upon learned fear in young rats. $D e-$ velopmental Psychobiology, 10, 25-32.

Hinderliter, C. F., Webster, T., \& Riccio, D. C. (1975). Amnesia induced by hypothermia as a function of treatment-test interval and recooling in rats. Animal Learning \& Behavior, 3, 257-263.

LASHLEY, R. L., RichaRDSON, R., \& RiCCIO, D. C. (1987). ACTH- and noncontingent footshock-induced recovery of an extinguished passive avoidance response. Physiology \& Behavior, 40, 677-680.

Mactutus, C. F., FereK, J. M., \& Riccio, D. C. (1980). Amnesia induced by hyperthermia: An unusually profound, yet reversible memory loss. Behavioral \& Neural Biology, 30, 260-277.

Mactutus, C. F., McCutcheon, K., \& Riccio, D. C. (1980). Body temperature cues as contextual stimuli: Modulation of hypothermiainduced retrograde amnesia. Physiology \& Behavior, 25, 875-883.

Mactutus, C. F., \& Riccio, D. C. (1978). Hypothermia-induced retrograde amnesia: Role of body temperature in memory retrieval. Physiological Psychology, 6, 18-22.

MAYES, J. F., \& DEVIETTI, T. L. (1971). A comparison of state dependent learning induced by electroconvulsive shock and pentobarbital. Physiology \& Behavior, 7, 717-721.

MilleR, R. R., \& SPRINGER, A. D. (1972). Induced recovery of memory in rats following electroconvulsive shock. Physiology \& Behavior, 8, 645-651.

Miller, R. R., \& SPRinger, A. D. (1973). Amnesia, consolidation and retrieval. Psychological Review, 80, 69-79.

MILLER, R. R., \& SPRINGER, A. D. (1974). Implications of recovery from experimental amnesia. Psychological Review, 81, 470-473.

NiELSON, H. C. (1968). Evidence that electroconvulsive shock alters 
memory retrieval rather than memory consolidation. Experimental Neurology, 20, 3-20.

OverTon, D. A. (1964). State-dependent or "dissociated" learning produced with pentobarbital. Journal of Comparative \& Physiological Psychology, 57, 3-12.

Overton, D. A. (1968). Dissociated learning in drug states (statedependent learning). In D. H. Efron, J. O. Cole, J. Levine, \& R. Wittenborn (Eds.), Psychopharmacology: A review of progress, 1957-1967 (pp. 918-930) (U.S. Public Health Service Publication No. 1836). Washington, DC: U. S. Government Printing Office.

OverTon, D. A. (1984). State dependent learning and drug discrimination. In L. L. Iverson \& S. H. Snyder (Eds.), Handbook of psychopharmacology (Vol. 18, pp. 59-127). New York: Plenum.

Quartermain, D., McEwen, B. S., \& Azmitia, E. C. (1970). Amnesia produced by electroconvulsive shock or cyclohexamide: Conditions for recovery. Science, 169, 683-686.

Richardson, R., Guanowsky, V., Ahlers, S. T., \& Riccio, D. C. (1984). Role of body temperature in the onset of, and recovery from, hypothermia-induced anterograde amnesia. Physiological Psychology, 12, 125-132.

Richardson, R., Riccio, D. C., \& MorilaK, D. (1983). Anterograde memory loss induced by hypothermia in rats. Behavioral \& Neural Biology, 37, 76-88.

RichaRDSON, R., Riccio, D. C., \& Steele, J. H. (1986). State-dependent retention induced by postacquisition exposure to pentobarbital or shock stress in rats. Animal Learning \& Behavior, 14, 73-79.
Rovee-Collier, C. K., \& Sullivan, M. W. (1980). Organization of infant memory. Journal of Experimental Psychology: Human Learning \& Memory, 6, 798-807.

SANTUCCI, A. C., \& RiCcio, D. C. (1987). Hypothermia-induced anterograde amnesia and its reversal in rats trained on a T-maze escape task. Physiology \& Behavior, 36, 1065-1069.

SCHACHTMAN, T. R., Brown, A. M., \& Miller, R. R. (1985). Reinstatement-induced recovery of a taste- $\mathrm{LiCl}$ association following extinction. Animal Learning \& Behavior, 13, 223-227.

SPEAR, N. E. (1978). The processing of memories: Forgetting and retention. Hillsdale, $\mathrm{NJ}$ : Erlbaum.

SPEAR, N. E. (1981). Extending the domain of memory retrieval. In N. E. Spear \& R. R. Miller (Eds.), Information processing in animals: Memory mechanisms (pp. 341-378). Hillsdale, NJ: Erlbaum.

Thompson, C. I., \& Neely, J. E. (1970). Dissociated learning in rats produced by electroconvulsive shock. Physiology \& Behavior, 5, 783-786.

Wright, D. C., \& ChuTE, D. L. (1973). State dependent learning produced by post trial intrathoracic administration of sodium pentobarbital. Psychopharmacologia, 31, 91-94.

(Manuscript received February 17, 1993; revision accepted for publication March 24, 1994.) 